\title{
FATORES DE INFLUÊNCIA PARA PARTICIPAÇÃO ELETRÔNICA: UMA VISÃO BASEADA NA TEORIA DA ESTRUTURAÇÃO INFLUENCE FACTORS FOR ELECTRONIC PARTICIPATION: A VIEW BASED ON STRUCTURATION THEORY
}

\author{
Josevana de Lucena Rodrigues ${ }^{1}$ \\ Hilmar Tadeu Chaves ${ }^{2}$
}

\section{RESUMO}

$\mathrm{Na}$ atualidade, o contexto da pesquisa empírica em participação eletrônica compreende uma diversidade de fontes de informação e tecnologias que impactam diretamente sobre a ação do cidadão. Esse contexto traz consigo um conjunto de resultados de pesquisa que ainda não consegue delinear totalmente os fatores de influência para esse tipo de participação. Nesse sentido, a Teoria da Estruturação se apresenta como uma alternativa eficaz para este ensaio teórico, trazendo consigo a necessidade de envolver, ao mesmo tempo, aspectos institucionais, coletivos e motivadores intrínsecos aos indivíduos. Assim, busca-se discutir os dois conceitos-chave desta teoria: agência e estrutura, relacionando-os com as teorias de uso das tecnologias nas organizações, afim de compreender os fatores influenciadores da participação eletrônica para os cidadãos, a partir de uma revisão da literatura cujo norte é a Participação Eletrônica e a Teoria da Estruturação. Os cidadãos, restritos a um millieau que auxilia a configurar sua existência e realidade, tendem a buscar uma certa segurança ontológica em sua participação eletrônica, de modo a assegurar que a sua realidade de aceitação junto ao seu grupo social não irá se modificar, facilitando a manutenção das condições que governam a continuidade de estruturas já dadas e, portanto, da reprodução dos sistemas sociais. Deste modo, as recompensas relacionadas à melhoria do bem-estar social produzido pela participação devem ser significativamente maiores do que o risco produzido pela possibilidade de conflito com os seus e perda do espaço de aceitação do grupo e consequentemente perda da segurança ontológica.

1 Doutoranda em Administração pela Universidade da Amazônia (UNAMA). Mestra em Ciências da Comunicação pela Universidade Federal do Amazonas (UFAM). Administradora vinculada à Universidade do Estado do Amazonas (UEA). E-mail: josevana@gmail.com

2 Doutorando em Administração pela UNAMA/SER. Mestre em Desenvolvimento Rural e Gestão de Empreendimentos Agroalimentares pelo IFPA/Universidad de Alicante. Especialista em Administração Financeira pela UFPA. Consultor de Empresas da HC Consultoria Ltda. Professor de Administração na Escola Superior da Amazônia (ESAMAZ). E-mail: hilmar.chaves@gmail.com 
Palavras-chave: Participação Eletrônica. Teoria da Estruturação. Fatores Influenciadores. Governo. Tecnologia-em-prática.

\begin{abstract}
The context of empirical research in electronic participation nowadays comprises a diversity of sources of information and technologies that directly impact citizen action. This context brings with it a set of research results that still can not fully delineate the influence factors for this type of participation. In this sense, the Structuration Theory presents itself as an effective theoretical lens for this theoretical essay, since it brings the need to involve at the same time, institutional and collective aspects and intrinsic motivators to individuals. Thus, this paper aims to discuss the two key concepts of this theory: agency and structure, relating them to theories of use of technologies in organizations, in order to understand more accurately the factors influencing electronic participation for citizens, from a review of literature that had as its focus the Electronic Participation and Structuration Theory. Citizens, restricted to a millieau who helps to shape their existence and reality, tend to seek a certain ontological security in their electronic participation, in order to ensure that their reality of acceptance with their social group will not change, facilitating the maintenance of the conditions that govern the continuity of structures already given and therefore of the reproduction of social systems. Thus, the rewards related to the improvement of the social welfare produced by the participation must be significantly greater than the risk produced by the possibility of conflict with theirs and loss of the acceptance space of the group and consequent loss of ontological security.
\end{abstract}

Keywords: Electronic Participation. Structuration Theory. Influence Factors. Government. Technology-in-practice.

\title{
1 INTRODUÇÃO
}

O contexto de participação eletrônica da atualidade dialoga diretamente com alguns aspectos controversos do mundo online, tais como bots, sistemas de informação programados para disseminação de conteúdo digital (RUEDIGER, 2017), desinformação programada ou não premeditada (TUFEKCI, 2017), além da crescente preocupação com métricas (MERGEL, 2017; KAGARIZE; ZAVATTARO, 2017). Em paralelo, continua em voga a necessidade de consolidação das democracias, especialmente em países periféricos.

Nesse cenário, o conceito de participação eletrônica se desenrola, a partir da capacidade de oferta por parte do governo de possibilidades de participação e abertura para tomadas de decisão mais colaborativas, tendo em vista que já não existe a barreira da copresença física (OECD, 2001; MACINTOSH, 2006; SAEBO et al., 2008; ONU, 2014). E por sua vez, do lado da demanda ou do cidadão, a participação eletrônica consiste em uma capacidade cívica de se informar e interagir com o governo de forma colaborativa. Todavia, cantada com esperança pelos teóricos até meados de 2014, a participação eletrônica tem paulatinamente falhado ao longo dos últimos anos (BRIGHT; MARGETT, 2016). 
Decorre desta conjunção de conceitos que a participação eletrônica engendra um conjunto de capacidades cívicas e tecnológicas, tanto por parte do cidadão, quanto pelo governo. Estas capacidades se configuram em fatores que influenciam diretamente na tomada de decisão para participação em assuntos do governo. Entretanto, a maioria dos trabalhos que buscam investigar os determinantes e fatores influenciadores da participação eletrônica tem focado especificamente em fatores psicológicos ou em fatores sociológicos de organização dos grupos de participantes, o que torna a literatura da área carente de perspectivas que envolvam uma visão mais holística do fenômeno.

Como resposta a esta problemática, a Teoria da Estruturação surge como uma das possíveis lentes teóricas que permitiriam um olhar diferenciado sobre os fatores influenciadores da participação eletrônica, inclusive por ser apontada como uma teoria ampla que tem colaborado para que pesquisadores das mais diversas áreas possam perceber deficiências fundamentais em seus campos de conhecimento (BRYANT, 1999). Deste modo, este ensaio teórico toma por base a seguinte pergunta norteadora: Em que medida o campo de estudos em participação eletrônica se beneficia das ideias da Teoria da Estruturação?

Assim, este trabalho se destina a discutir os dois conceitos-chave desta teoria: agência e estrutura, relacionando-os com as teorias de uso das tecnologias nas organizações, afim de compreender os fatores influenciadores da participação eletrônica para os cidadãos. Para isso, utilizou-se de uma revisão da literatura, objetivando esclarecer os principais aspectos da participação eletrônica, bem como levantou-se os fatores influenciadores apontados nas pesquisas empíricas. Do mesmo modo, utilizou-se de revisão da literatura para, de modo didático, reconhecer os traços dos processos estruturacionais que se engendram entre fatores estruturais e motivacionais (ou seja, aqueles mais inerentes a agência dos indivíduos), inclusive considerando o importante papel da tecnologia como elemento estruturador da ação social, conforme apontado pela teoria da tecnologia-em-prática (ORLIKOWSKI, 1992, 2000, 2009; LEONARDI, 2013).

Os fatores estruturais foram compreendidos como aqueles referentes às regras e aos recursos dispostos como propriedades dos sistemas sociais, auxiliando nos processos de significação, dominação e legitimação que reproduzem a própria sociedade (GIDDENS, 2009). São os fatores que estão envoltos no contexto da participação, condicionando a tomada de decisão que o cidadão terá em participar. Contudo, é importante assinalar que as motivações pelas quais os cidadãos participam ou se engajam, ainda não é de todo conhecido na literatura (SABIONI et al., 2018).

Desta forma, o trabalho divide-se nas seguintes seções: (1) Governo e as ideias de participação, em que se pretende discutir as ideias de governo e sua relação com participação; (2) O desenvolvimento da participação eletrônica, em que se destaca o funcionameto da participação eletrônica, a partir de estudos em diferentes países e, finalmente, (3) Fatores de influência da participação cidadã, em que são analisadas as influências de conceitos importantes da teoria da estruturação no campo da participação. E, por fim, as Considerações Finais.

\section{GOVERNO E AS IDEIAS DE PARTICIPAÇÃO}

No decorrer da história da administração pública, Foucault (1991) auxilia na compreensão da mentalidade das organizações públicas em seus processos de "governar". Destacando que a 
preocupação com as questões relativas à população do território surge apenas em meados do século XVIII, quando a ideia de monarquia e Estado absoluto vai aos poucos perdendo a força e os ideais democráticos começam a influenciar a ação estatal. É nesse momento que a até então chamada "arte de governar" começa a ganhar status de ciência, vinculando-se primeiramente à economia política e posteriormente às ciências administrativas.

Será a partir da perspectiva de administração como ciência que surge também a burocracia através da construção de um saber econômico que permeia ideias de eficiência administrativa e hierarquização de processos. Em 1887, o artigo seminal de Wilson contribui para a divisão sistêmica entre administração e política. Severamente influenciada pela técnica da administração científica, a administração pública passa por várias reformas, que paulatinamente irão retirar o cidadão da discussão dos assuntos do governo (WILSON, 1887).

No Brasil, após sucessivos períodos em que a democracia não foi o ideal do Estado, iniciaramse a partir dos anos de 1980, movimentos populares para democratização dos processos de elaboração de políticas públicas. Segundo Paula e Keinert (2016), isso culminou com a Constituição Federal de 1988, denominada "Constituição Cidadã". Entretanto, conforme o tempo avança e o Estado brasileiro se estabiliza, tanto democraticamente, quanto economicamente, surge a necessidade de melhoria da qualidade dos serviços públicos oferecidos, o que ancorado aos ideais neoliberais, baseia a reforma do Estado de 1995, cujo principal mentor foi Bresser-Pereira $(1996,1998)$.

Uma grande crítica a essa reforma foi a diminuição da importância dos espaços de deliberação públicas até então idealizados na Constituição de 1988, em detrimento de maior poderio dos burocratas que tinham maior exigência de competência técnica e administrativa, onde supostamente os cidadãos não tinham, a não ser que estes se organizassem em organizações nãogovernamentais, formalmente instituídas, as quais era dado o pressuposto de parceria com o Estado para a realização de serviços públicos.

Acredita-se que foi a partir do emaranhado dessas ideologias que surge no Brasil uma "confluência perversa" de dois conceitos de participação: (1) a participação se daria como consequência do adensamento da cidadania e da democracia; e (2) a participação se associa à diminuição do papel do Estado e isenção deste como garantidor de direitos (DAGNINO, 2005). Esses dois entendimentos são problemáticos para a compreensão do tema, o primeiro conceito adota uma perspectiva evolucionista dos processos democráticos que não é necessariamente real, enquanto o segundo conceito retira do Estado brasileiro sua função de garantidor de direitos.

Assim, conforme explica Piñedo-Nebot (2004), a necessidade da participação está dirigida por um conjunto de regras de participação direta e também representativa, em instituições cujo regime interno está delineado pelos participantes e com recursos distribuídos, segundo métodos objetivos baseados em critérios gerais, como também em critérios técnicos.

De modo semelhante, o trabalho de diálogos entre Brasil e União Europeia, realizado pelo Instituto de Pesquisa Econômica Aplicada IPEA (2017), esclarece as diferenças entre as duas principais concepções de participação democrática, aquela de viés representativa e a outra de viés direto ou deliberativo, conforme verifica-se no Quadro 1. 
Quadro 1: Diferenças entre perspectivas de participação democrática

\begin{tabular}{|c|c|c|}
\hline CONCEITO & CARACTERÍSTICAS & CRÍTICAS \\
\hline $\begin{array}{c}\text { PARTICIPAÇÃO } \\
\text { DEM OCRÁTICA } \\
\text { REPRESENTATIVA }\end{array}$ & $\begin{array}{l}\text { - Vinculada a um método político de competição } \\
\text { entre os líderes (elite), pelos votos dos indivídu- } \\
\text { os, em eleições livres e periódicas; } \\
\text { - Somente por meio do procedimento eleitoral é } \\
\text { que a maioria pode exercer o controle sobre os } \\
\text { representantes eleitos, ou seja, não os/as recon- } \\
\text { duzindo ao mandato político; } \\
\text { - A igualdade política seria vinculada ao direito } \\
\text { de todos ao sufrágio universal e à existência de } \\
\text { igualdade de oportunidades de acesso aos canais } \\
\text { de influência sobre os líderes; } \\
\text { - O nível de participação da maioria não deve } \\
\text { crescer acima do mínimo necessário, a fim de } \\
\text { manter o método democrático (máquina eleito- } \\
\text { ral) funcionando. }\end{array}$ & $\begin{array}{l}\text { - Procura estabilizar a tensão } \\
\text { controlada entre democracia e } \\
\text { capitalismo; } \\
\text { - Prioridade conferida à acumu- } \\
\text { lação de capital em relação à } \\
\text { redistribuição social; } \\
\text { - Limitação da participação ci- } \\
\text { dadã, tanto individual, quanto } \\
\text { coletiva; } \\
\text { - Sobretudo em países em de- } \\
\text { senvolvimento, esconde e man- } \\
\text { tém estruturas de dominação e } \\
\text { opressão forjadas historicamen- } \\
\text { te e perpetradas pelo Estado. }\end{array}$ \\
\hline $\begin{array}{c}\text { PARTICIPAÇÃO } \\
\text { DEM OCRÁTICA DIRETA } \\
\text { OU DELIBERATIVA }\end{array}$ & $\begin{array}{l}\text { - Não limitada apenas ao voto; } \\
\text { - Permite que as decisões coletivas sejam aceitas } \\
\text { mais facilmente pelo indivíduo, uma vez que to- } \\
\text { maram parteno processo decisório; } \\
\text { - Para que os indivíduos sejam capazes de parti- } \\
\text { cipar efetivamente do governo de um Estado } \\
\text { nacional, as qualidades necessárias a essa parti- } \\
\text { cipação devem ser fomentadas e desenvolvidas } \\
\text { em nível local, por meio da democratização das } \\
\text { estruturas de autoridade em todos os sistemas } \\
\text { políticos. }\end{array}$ & $\begin{array}{l}\text { - Excesso de demandas sociais } \\
\text { desestabilizariam o sistema po- } \\
\text { lítico e sobrecarregariam finan- } \\
\text { ceiramente o Estado; } \\
\text { - Risco de manutenção de rela- } \\
\text { ções clientelistas em uma socie- } \\
\text { dade sem recursos cognitivos e } \\
\text { educacionais à participação. }\end{array}$ \\
\hline
\end{tabular}

Fonte: Adaptado de IPEA ${ }^{3}$ (2017).

Nesse contexto, dois possíveis conceitos de participação surgem, o primeiro ancorado nas ideias neoliberais, em que o Estado é menor, a burocracia foca na eficiência técnica, aportada na informação levantada por pesquisa e possui o poder de decisão final, junto aos atores políticos, que são os verdadeiros detentores de poder. Por conseguinte, a participação eletrônica seria definida pela capacidade de utilização da tecnologia para o fomento de interação subsidiada de informação com o cidadão para a tomada de decisão pública pelos burocratas e decisores formalmente atribuídos.

No outro contexto, que defende e fomenta a participação direta, os movimentos sociais e um Estado mais aberto, a participação eletrônica seria a capacidade de utilização das tecnologias para aprimorar as interações com o cidadão, de forma a possibilitar democracia direta, com influência significativa do cidadão na tomada de decisão pública.

Em ambas as visões de participação, dois aspectos serão fundamentais para o desenvolvimento de uma participação eletrônica efetiva: informação e poder compartilhados para com o cidadão. Assim, parte-se para o desenvolvimento das bases para a discussão dos conceitos de participação eletrônica.

\footnotetext{
O quadro foi retirado de documento oficial do IPEA, a partir de alguns trabalhos relevantes na área, tais como o de Carole Pateman, no livro Participação e Teoria Democrática (1992) e Boaventura de Sousa Santos, no livro Democratizar a democracia (2002).
} 


\section{O DESENVOLVIMENTO DA PARTICIPAÇÃO ELETRÔNICA}

A partir dos anos 2000, alguns autores e organismos internacionais apontam para o surgimento de um novo modelo de Administração Pública voltado para "Governança Responsiva” (ONU, 2005), também apontada como "New Public Governance" (OSBORNE, 2006 apud BRAGA; GOMES, 2016) ou "Digital Era Governance" (DUNLEAVY, et al., 2006). Destaque-se que este não é um novo paradigma, mas uma tendência geral de melhoria e desenvolvimento dos serviços públicos pelo incremento de tecnologias.

Aparticipação eletrônica surge nesse contexto de ampliação do alcance das ideias de governança, desenvolvida como “contraposta à noção de governo” (POLAT, 2005 apud BRAGA; GOMES, 2016), referindo-se à participação de diferentes atores sociais, advindos de diferentes grupos e comunidades em uma estrutura que possibilita mudanças nas relações entre Estado e sociedade.

Outra questão relevante neste quadro contextual é a relação entre os estudos de participação eletrônica e governo eletrônico, surgidos a partir do campo da democracia eletrônica (SUSHA; GRONLUND, 2012). Esse campo de estudos foca suas atenções no papel das TICs (Tecnologias da Informação e Comunicações) para apoiar e facilitar objetivos democráticos e ainda que a participação eletrônica esteja envolvida diretamente com estes aspectos democráticos, é um campo que se desenvolve independente (SANFORD, 2007), pois embora a pesquisa em participação eletrônica possa aparentar ser de um domínio bastante instrumental, seu escopo é mais amplo e abrange a participação dos cidadãos em praticamente qualquer serviço público e não necessariamente restrito ao campo político ou estritamente relacionado à governança.

A participação eletrônica está relacionada também com "oportunidades de consulta e diálogo entre governo e cidadãos, utilizando uma série de ferramentas de TIC" (MACINTOSH, 2004; ROSE, et al., 2007; CUNHA, et al., 2014). Mas Susha e Grounlund (2012) ao sistematizar os tópicos pesquisados na área de participação eletrônica, visualizaram a preocupação com o ambiente em que ocorre o fenômeno, dividindo-o em (a) estrutura social, (b) propriedades dos sistemas políticos e (c) fatores tecnológicos, enquanto por outro lado, existe também a busca por respostas junto aos stakeholders do processo participativo eletrônico que são constantemente mencionados como (1) o próprio governo e administração e (2) cidadão e organizações coletivas.

Assim, Seo e Hasan (2015), em um trabalho comparativo entre governos do sul da Ásia, apresentam a participação eletrônica como se referindo ao "processo de tornar os cidadãos envolvidos na política e na tomada de decisões, utilizando-se de TICs, de modo a melhorar a administração governamental através de contribuições populares de forma colaborativa e deliberativa".

Piñedo-Nebot (2004), em um estudo comparativo sobre as práticas participativas ocorridas na cidade de Porto Alegre (Brasil) e em algumas cidades espanholas, chama a atenção para alguns desses aspectos citados por Susha e Gronlund (2012), tais como as garantias constitucionais que darão direito a todos participarem igualmente. Piñedo-Nebot (2004, p. 03) destaca que "a utilização prolongada do pressuposto de participação cria um contexto favorável para estimular um novo comportamento político, o que supõe um ethos político diferente (...) permitindo uma cidadania mais consciente, mais crítica e mais exigente". Entretanto, quando a participação se desloca para o ambiente virtual, não há consenso sobre as implicações dos movimentos de participação eletrônica. 
Ainda tratando de ambiente, surge nessa imbricada rede de pressupostos a necessidade de se discutir dívida digital, que tem sido apontada como uma das formas de replicação da exclusão social tradicional (VICENTE; NOVO, 2014), tendo em vista que os mesmos grupos excluídos socialmente, também estão excluídos digitalmente. Uma vez que grande parte dos serviços públicos tem se digitalizado, a dívida digital replicando a estrutura social impossibilita uma disrupção das regras do sistema político.

Para Shao e Wang (2017, p. 698), em um estudo sobre a esfera pública chinesa após o advento das mídias sociais, "a participação online em redes sociais não apenas empodera os usuários no mundo digital, mas também modifica profundamente a vida real.”. Em paralelo, a pesquisa de Kavanaugh et al. (2014), realizada em diferentes cidades norte-americanas, traz algumas questões problemáticas à discussão. A primeira delas se refere a uma vinculação entre nível educacional e participação, onde comparando pessoas de diferentes grupos e classes sociais, situados em ambiente diverso de urbanização, se constatou que havia pouca correlação entre alto nível educacional e participação eletrônica para fins cívicos. Da mesma maneira, o comportamento extrovertido, típico de líderes, não tinha relações com a participação em ambiente online.

De modo semelhante, Vicente e Novo (2014), em uma pesquisa na Espanha, sobre dois tipos de participação eletrônica (expressão de opiniões e participação em petições e consultas online), notaram que uma vez que as pessoas estejam online, as diferenças socioeconômicas tendem a desaparecer, exceto pela variável gênero, pois no estudo, as mulheres foram menos participativas. E de modo contrário, pessoas desempregadas tenderam a ser mais participativas. A única confirmação do estudo se deu no tocante àquelas pessoas que possuíam habilidades digitais, ou seja, tinham familiaridade e conhecimento no uso de ferramentas de TICs. O que significa dizer que do ponto de vista do cidadão, as habilidades digitais são importantes preditores da participação eletrônica, o que já havia sido apontado nos estudos de Anduiza et al. (2010), Best e Krueger (2005) e Krueger (2002).

Por outro lado, Pinho (2011), refletindo sobre democracia, sociedade e internet, traz um quadro interessante sobre a participação eletrônica, a partir da emergência de uma agenda pós-moderna na internet, que está baseada em relações fugazes que se desfazem muito facilmente, constituindo-se na forma atual de fazer política, sem grandes narrativas e com demandas mais específicas, tais como feminismo ou ambientalismo.

Somada a afirmação teórica de Pinho (2011), de que a internet fragmenta o coletivo em diversos grupos de interesse, Susha e Gronlund (2012) chamam a atenção para o potencial da internet em criar barreiras à participação pública genuína, servindo para propósitos não democráticos, de confirmação e manipulação midiática, estes seriam alguns dos perigos da participação eletrônica.

Um exemplo destes perigos foi apontado nos estudos coordenados por Ruediger (2017), no Brasil, demonstrando que desde as eleições de 2014, perfis automatizados motivaram debates políticos no site de rede social Twitter. Esses perfis automatizados, também conhecidos como robôs, trabalham massificando postagens e conteúdos, portanto manipulando debates políticos.

García (2014) traz a participação eletrônica como uma última fase de um governo digital, após algumas fases como presença, divulgação e supervisão. Estas fases sublinham o fato de que a participação da sociedade, via governo eletrônico tem como principais pressupostos as oportunidades oferecidas pelos governos (LIDÉN, 2016), com programas governamentais 
que encorajem a participação, mas também da propensão dos cidadãos em se utilizar destes mecanismos (BRAGA; GOMES, 2016).

Neste sentido, usuários de internet vivendo em regiões de administrações públicas com maiores graus de desenvolvimento de serviços públicos online estarão mais propensos a participar online, juntando-se a petições online ou fazendo parte de consultas públicas, do que aqueles usuários de internet que vivem em regiões com poucos serviços públicos online (VICENTE; NOVO, 2014).

Finalmente, inserida no escopo de governo eletrônico, a participação eletrônica é apresentada por Seo e Hasan (2015) como um dos componentes do governo eletrônico, ao lado dos serviços eletrônicos e da administração eletrônica, quando o governo se apropria das TICs para melhor se organizar e gerir seus recursos, em que vale ressaltar essa utilização maciça de TICs gera muita informação importante para os aspectos de governança e aqueles delineadores das necessidades de participação social.

\section{FATORES DE INFLUÊNCIA PARA PARTICIPAÇÃO ELETRÔNICA}

A participação eletrônica, inserida dentre as formas de participação democrática, pode provocar mudanças nas estruturas das instituições públicas e consequentemente nas formas de reprodução da própria sociedade. Neste sentido, faz-se interessante a proposta de trabalho de Giddens (2000) desenvolvida a partir da compreensão de que as diferentes correntes teóricas não conseguiram abarcar o fenômeno da relação entre instituições e ação dos indivíduos de forma a conseguir responder o relativo grau de autonomia e dependência entre estas duas categorias.

O desenvolvimento da ideia de Dualidade da Estrutura implica na Teoria da Estruturação, a qual se funda na noção de que existe um "caráter fundamentalmente recursivo da vida social e expressa a dependência mútua entre estrutura e agência" (GIDDENS, 2000, p. 43). Nas próximas seções, este trabalho discute os dois conceitos-chave desta teoria: agência e estrutura. Em seguida, as teorias relacionadas ao uso das tecnologias nas organizações serão discutidas, a partir do objeto participação eletrônica, de modo a iniciar a discussão das motivações imbricadas na agência da participação eletrônica.

\subsection{CONCEITOS CHAVE INTER-RELACIONADOS: AGÊNCIA E ESTRUTURA}

No desenrolar da teoria da estruturação, dois conceitos-chave operacionalizam uma sequência de relações que são reiteradamente destacadas: agência e estrutura. Entretanto, nem agência, nem estrutura seguem as mesmas características que outrora já haviam sido explicadas por teóricos funcionalistas, estruturalistas e até mesmo interpretativistas. No cerne do debate sobre estes conceitos está a questão da relação tempo e espaço, as ações acontecem na relação entre essas duas entidades. Assim, a agência não é uma ação isolada no tempo, mas um "fluxo contínuo de conduta", que envolve a intervenção em um mundo maleável, de forma causal, seja concreta ou projetada. Devido a sua subordinação à questão temporal, a agência não pode ser completamente elucidada sem o contexto dos "modos de atividade historicamente localizados" (GIDDENS, 2000, p. 14).

Enquanto isso, a estrutura, que se relaciona intrinsecamente a dois outros conceitos-chave da teoria, sejam eles sistema e estruturação, não pode ser confundida com estes. Estrutura é estabelecida 
como "regras e recursos ou conjuntos de relações transformacionais, organizadas como propriedades dos sistemas sociais (propriedades estruturais) ". Sistema, por sua vez, será "o conjunto de relações reproduzidas entre os atores ou coletividades, organizadas como práticas sociais regulares". Deste modo, a estruturação dar-se-á como "as condições que regem a continuidade da transformação das estruturas e a reprodução dos sistemas sociais" (GIDDENS, 2000, p. 16).

De forma didática e como exemplo, pode-se pensar em um cidadão brasileiro de classe média e no seu interesse em participar nas decisões públicas, seja para manutenção de seus interesses, seja para mudança de algo que não está satisfazendo-o. Teoricamente, ele é livre para participar, mas sua liberdade "conversa" com as estruturas sociais existentes, com seu histórico no mundo, as regras que conhece e aqueles recursos de conhecimento social, humano e tecnológico que ele possui. Essas estruturas não o irão moldar e talvez não o limitem sempre, tendo em vista que cada pessoa possui uma sequência de intenções, as quais até mesmo a própria pessoa desconhece, questões de sua psique, como o desejo de pertencimento, reconhecimento e liderança, por exemplo. Giddens (2000) destaca que a agência das pessoas estará atrelada aos recursos e regras existentes, mas como em um jogo de crianças, essas regras são modificadas ao longo do tempo, conforme o interesse dessas crianças, a localização da brincadeira, entre outros fatores que agem para que as crianças modifiquem continuamente suas regras de brincar.

Assim, a leitura do mundo social perpassa sua historicidade, a visão da agência que também vai causar e ser causada por outras agências e conjuntos de regras e recursos os mais diversos possíveis. Ao longo do tempo, a teoria de Giddens (2000) vai se tornando um importante suporte para compreensão do uso da tecnologia em organizações, este uso é um dos principais aspectos da participação eletrônica. Portanto, a próxima seção irá destacar os trabalhos relacionados ao uso de tecnologias e organizações que se utilizam de alguns conceitos ora discutidos.

\subsection{DUALIDADE DA ESTRUTURA NOS ESTUDOS SOBRE TECNOLOGIA EM ORGANIZAÇÕES}

No início das pesquisas sobre uso de tecnologias em organizações, os estudiosos buscavam compreender o efeito da tecnologia sobre a estrutura organizacional, gerando uma visão contingencial do tema, o que acabava por originar uma relação determinística entre o uso das tecnologias e suas implicações nas organizações. A partir da segunda metade dos anos 1980, Barley (1986) começa a questionar essa acepção, afirmando que as tecnologias poderiam vir a ser reavaliadas ou reimaginadas pelas pessoas que as utilizam, para isso o referido autor empregou a teoria da estruturação de Giddens (1979,1984) (LEONARDI, 2013, p. 62).

Assim, a discussão sobre a dualidade da estrutura é iniciada nos estudos concernentes ao uso organizacional das tecnologias, em que Barley (1986 apud LEONARDI, 2013) buscou a ideia de comunicação interpessoal como operacionalização do conceito de agência, enquanto a estrutura formada era caracterizada pela estrutura de tomada de decisão das organizações. O uso da tecnologia então vinculava a agência à estrutura, pois o grupo alterava sua estrutura, toda vez que conhecia e usava determinada tecnologia e a difundia na organização.

Esse conceito foi adaptado por Poole e DeSanctis (1990), no que chamaram teoria da estruturação adaptativa, alterando apenas a definição de estrutura afetada pela agência comunicação, 
que de estrutura de tomada de decisão, passou a ser chamada de normas do grupo. Então, o uso da tecnologia vinculava a comunicação interpessoal às mudanças ou constituição das normas de determinado grupo social, dentro das organizações.

O salto teórico se dá nos trabalhos de Orlikowski (1992) com o modelo da dualidade da tecnologia, em que o próprio uso da tecnologia toma a forma da agência, assim o uso da tecnologia é o que irá ao longo do tempo da organização alterar ou confirmar a estrutura organizacional. De modo que atores com poder na organização definiriam as práticas de uso da tecnologia, gerando significados de uso que seriam geradoras de poder, legitimação e dominação na organização. Mas, ao mesmo tempo, o modelo prevê que a agência dos usuários da tecnologia poderia se rebelar dessa estrutura imposta, alterando-a.

Um exemplo prático é um grupo gestor que adota determinada tecnologia na organização, sem ouvir os demais empregados, e atribuindo processos de trabalho e diferenças de acesso entre eles. Entretanto, conforme o uso avança na organização, o grau de conhecimento (recursos) efetua uma diferença nas regras de acesso, que ao longo do tempo se alteram entre os funcionários, mudando a legitimidade do grupo detentor do conhecimento. Nos dizeres de Leonardi (2013, p. 65), "o uso da tecnologia se torna em fator constitutivo da estrutura organizacional".

Contudo, Orlikowski (2000) não fica inteiramente satisfeita com esse modelo e avança no sentido de trazer mais para o centro de análise a tecnologia. A partir das lentes da prática, o uso da tecnologia se desenvolve em uma "tecnologia-em-prática" (tecnology-in-practice), constituída como "uma estrutura particular de uso da tecnologia", substituindo os outros quadros mais abstratos de estrutura, tais como tomada de decisão, normas de grupo e até mesmo legitimação. Deste modo, a agência de uso da tecnologia se acumula através do tempo em certos padrões de uso que irão se transformar em uma estrutura, as quais as pessoas irão usar para melhor realizar seus trabalhos ou interação com outros.

Isso vai ocorrer através de processos interpretativos, ou seja, signos culturais que circularão entre aquele grupo de pessoas que se utiliza da tecnologia e que pode a transformar, conforme o significado muda. Um ótimo exemplo desse uso que se consolida com o tempo é a tecnologia das mídias sociais, elaborada com fins de interação social, foi amplamente adotada por organizações empresariais de todo o mundo, aproximando clientes e empresas. Apesar de não adotadas por todas as organizações públicas, é perceptível que o comportamento de uso de mídias sociais direcionado às empresas privadas, é adotado também nas interações entre cidadãos e organizações públicas. As relações visualizadas neste estudo entre as teorias ora estudadas e o fenômeno de interação governocidadão e cidadão-governo serão debatidas na seção abaixo.

\subsection{PARTICIPAÇÃO ELETRÔNICA, TECNOLOGIA E MOTIVAÇÃO NA DUALIDADE DA ES- TRUTURA}

A participação eletrônica, desde a concepção de Sanford e Rose (2007), define um papel central do governo no fomento dos processos participativos. Apesar de crescentes avanços tecnológicos na interação governo e cidadão, o que tem sido registrado em muitas pesquisas é o frequente fracasso de iniciativas do tipo, especialmente em países desenvolvidos e com amplo acesso à internet. 
Ainda que diferentes métodos e tecnologias tenham sido aplicadas, em paralelo muitos países em desenvolvimento também apresentam estágios precários no desenvolvimento da temática.

Assim, a participação eletrônica segue causando muitas dúvidas e diferentes constatações. As pesquisas não conseguem convergir quanto ao perfil do cidadão participante, nem quanto a efetividade do conteúdo compartilhado pelos governos. Em paralelo, a rápida evolução das TICs requer constante aprendizagem por parte do cidadão, como também o desenvolvimento de capacidades dos entes estatais.

Daí que o fenômeno da participação eletrônica deve levar em consideração aspectos do processo de abertura governamental e de adoção tecnológica de governos e cidadãos. A área de abertura governamental perfaz movimentos de reforma da estrutura burocrática para a criação de ambientes de transparência e accountability e por último, mas não menos importante, de metodologias que estimulem o compartilhamento de poder com os cidadãos em intensidades e modos que variam conforme o caso.

Entretanto, a abertura governamental depende da capacidade do governo em conseguir adotar e usar tecnologias de informação que sejam acessíveis aos cidadãos. É nesse quesito, que a teoria da tecnologia-em-prática pode dar seu contributo, pois o uso particular de uma tecnologia repetida ao longo do tempo se consolida em um conjunto de regras e recursos. Dessa forma, quando pensada em conjunto com a problemática da participação eletrônica, a tecnologia-em-prática não se constituirá apenas nas regras de uso adotadas pela organização governamental, mas nas formas de uso levantadas pelo cidadão médio.

Essa problemática, que expande a fronteira da organização não é inteiramente abordada pela tecnologia-em-prática, mas pode ser mais bem compreendida em um esforço de retomada conceitual das ideias da Teoria da Estruturação. A maior parte dos estudos sobre a participação eletrônica pressupõe o papel da estrutura sobre a agência dos atores sociais ou foca suas asserções apenas na agência dos atores.

Ao conceituar de forma diferente aspectos relevantes que se situam no cerne da questão, tais como agência, significado, estrutura e regras, a Teoria da Estruturação pode visualizar as práticas sociais imbuídas de capacidade de negociação e interação, concebendo uma conduta humana detentora de relativo poder, não aceitando os extremos de determinismo ou liberdade absoluta, podendo dar base para uma análise mais completa das motivações que determinam a conduta dos agentes durante os processos participativos públicos, em especial, em ambiente eletrônico.

Outrossim, ao conceituar uma agência que está coagida e/ou facilitada pelas interações no espaço/tempo, a Teoria da Estruturação consegue auxiliar a compreensão do processo de virtualização da participação eletrônica, que engendra mecanismos de sobreposição espaço-temporal que podem fluidificar processos burocráticos consolidados e coagir atores que não possuem os recursos necessários para interação online, tornando os mecanismos de participação eletrônica facilitadores de assimetrias de poder que podem ter consequências perigosas nas democracias.

Portanto, longe de ser um canal neutro ou um mediador passivo, as TICs podem ser integralmente e ativamente parte da produção de conhecimento (SCOTT; ORLIKOWSKI, 2009), criando interferências que poderão ter grande alcance nas relações cidadão e governo. Dessa maneira, é importante analisar a tecnologia-em-prática imposta nas interações sociais ao longo da agência dos cidadãos. 
Através das lentes da estruturação, pode-se visualizar que existe uma interação entre as escolhas de usos das tecnologias pelas organizações públicas que devem necessariamente ser acompanhadas pelas escolhas de uso tecnológico dos cidadãos. Vários autores afirmam que existe uma série de determinantes que devem anteceder a escolha pública por elementos materiais de participação (PINHO, 2011; VICENTE; NOVO, 2014; SABIONI, et al., 2016).

Um desses "pré-requisitos" é a inclusão digital que pode ser definida como o acesso aos meios materiais tecnológicos e as habilidades digitais necessárias para o uso tecnológico. Essa inclusão digital pode ser visualizada como uma forma de recurso, através do desenvolvimento da ideia de habilidade digital, que se refere ao conhecimento através da prática continuada, perfazendo práticas interpretativas do uso da tecnologia. Desta feita, os recursos e regras conhecidos pelos cidadãos quando atuantes em processos de participação eletrônica são estruturas que possuem regras de conduta e interação em rede que não são escritas, mas detentoras de saberes tácitos que vão ser utilizados naquelas práticas situadas em ambiente virtual.

Mas a agência também pode ser produto direto de outras agências, como acontece, a partir das tomadas de decisão do governo, com mobilização extraparlamentares, surgidas em discussões dadas na esfera pública. Essa agência pode ser diretamente causada pela agência do governo, lugares em que existe um amplo uso das tecnologias de governo eletrônico, tendem a ter uma maior participação cidadã em projetos de participação eletrônica (VICENTE; NOVO, 2014). Piñedo-Nebot (2004) adverte que quanto mais o governo amplia as oportunidades de participação, mais os cidadãos participam de forma qualificada, "aprendendo a participar".

Existe aí uma relação direta entre duas agências, que ao longo do tempo irão agregar novas estruturas de tecnologia-em-prática, mas que por ora são também apoiadas em estruturas existentes, tais como aquelas referentes à estrutura social do município, no caso das prefeituras, e por outro lado, emergem a partir de tecnologias-em-prática de determinado artefato tecnológico utilizado, como é o caso das mídias sociais, que assumem tecnologias-em-prática próprias, as quais os governos devem se adaptar em seus objetivos e interações com os cidadãos.

Então, analisando sob a ótica da Teoria da Estruturação, especialmente com foco na ideia de dualidade da estrutura, a participação eletrônica é uma agência do governo, através do uso da TIC que influenciará a agência do cidadão. Entretanto, tanto a agência do governo, quanto a do cidadão sofrerão e influenciarão estruturas já dadas, especialmente as tecnologias-em-prática que formam uma estrutura que se relaciona com o uso em si da tecnologia, ou seja, no caso em voga as tecnologias-emprática são o conjunto de regras e recursos que regem o espaço online de interação.

Em contrapartida, Sabioni et al. (2016) apontam para o papel do contexto como influenciador da capacidade de um governo conseguir alcançar participação cidadã. Nesse aspecto, a estrutura municipal, formada por renda, formação educacional de ensino superior e acesso à infraestrutura de internet, é destacada por se desenvolver como uma estrutura dada, que trará algumas regras e recursos aos cidadãos, possibilitando-os como participantes diretos da interação com o governo.

Mais difíceis em sua compreensão estão os fatores motivacionais inerentes aos indivíduos. Phang e Kankanhalli (2005) apontam para diferentes perspectivas existentes na literatura para explicar os determinantes da participação cidadã, sendo elas: (1) Modelo de Participação Socioeconômico, na qual variáveis como renda, nível educacional são fatores preponderantes para participação; (2) 
Modelo Racional de Participação, na qual existe uma escolha entre custo e benefício da participação, fator que é parcialmente eliminado quando da participação eletrônica, devido aos ganhos muito residuais, quase sempre vinculados também à comunidade e o quase custo zero da interação; (3) Modelo do Voluntarismo Cívico, um dos mais usados, que aponta não apenas para as questões referentes a custos de participação, bem como para a vinculação de grupo e até mesmo político partidária, sendo uma extensão do modelo socioeconômico, destacando a influência dos recursos na participação; (4) Modelo dos Incentivos Gerais, que foca na percepção de benefício percebido pelo cidadão, ou seja, quanto o Estado está incentivando a participação, no processo digital, apesar do contexto aparentemente aberto, a participação em si, geralmente não irá trazer o benefício imediato; (5) Teoria do Capital Social, basicamente, vincula-se à ideia de que por fazer parte de uma rede que tem características participativas, o indivíduo participará como efeito disso.

Estas cinco perspectivas convergem para a perspectiva de que a estrutura irá determinar a conduta dos indivíduos, ignorando aspectos dos valores motivadores da conduta humana que podem ser determinantes para sua ação no mundo. Essa acepção parte da ideia de que toda conduta humana perpassa por aspectos motivacionais, racionalizados e que são nesses processos monitorados reflexivamente pelo próprio ator social. Nos dizeres de Giddens $(2009$, p. 7) "os motivos tendem a ter uma influência direta na ação apenas em circunstâncias relativamente incomuns, situações que, de algum modo quebram a rotina".

Quando o cidadão sai do seu motivador hedonista de "surfar" na internet e parte para um uso de mídias sociais que seja civicamente consciente, ele não parte apenas dos incentivos recebidos pelo Estado, que são poucos ou simplesmente nem existem. Também não o faz somente por ter os recursos para isso. Ele parte de uma necessidade prática dele, dada a oportunidade pelo Estado, tendo um costume de uso da tecnologia, somada aos fatores motivadores de sua ação no mundo.

O modelo de estratificação do self atuante (Figura 1) pode auxiliar na compreensão dos elementos interelacionados que se conjugam em movimentos anteriores à ação participativa.

Figura 1: Modelo de estratificação do agente

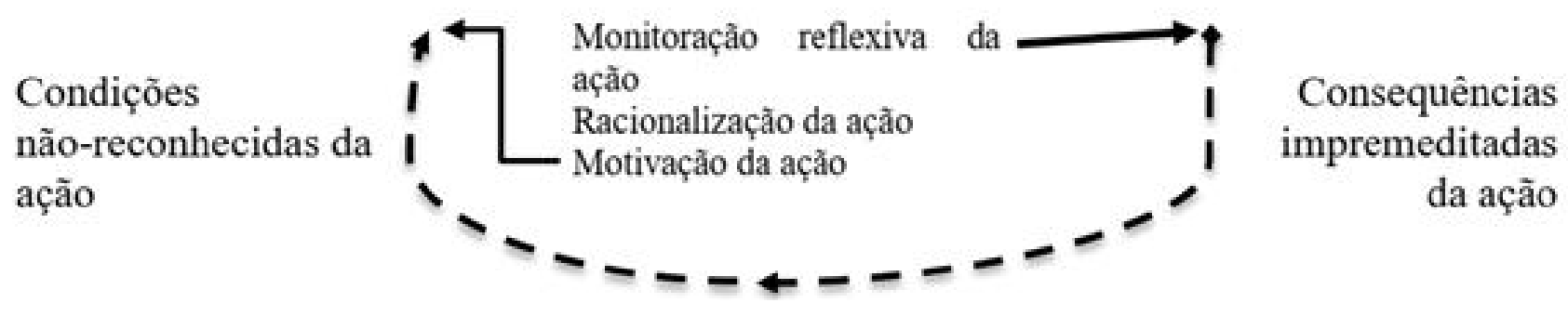

Fonte: Giddens (2000).

A teoria da estruturação aponta para uma diferenciação de motivação, racionalização e monitoração reflexiva da ação. Três construtos inteiramente vinculados entre si como conjuntos de procesos incrustados (Giddens, 2000, p. 4). Para distingui-los é necessário a compreensão de que o monitoramento reflexivo da ação se refere à intencionalidade humana como processo, pois existe um monitoramento rotineiro das próprias ações por parte dos seres que a compõem. É a capacidade de organizar mentalmente se há capacidade para ofertar ou realizar determinada demanda, situando-se, portanto, na consciencia prática e cotidiana. 
É importante assinalar que o monitoramento reflexivo da ação inclui o monitoramento do cenário de interação, e não apenas o comportamento dos atores particulares tomados separadamente, ou seja, se dá no âmbito do presente da ação. Por sua vez, diretamente vinculado ao monitoramento reflexivo da ação estará a racionalização da ação, de maneira que o agente consegue traçar discursivamente as razões que o levaram a realizar determinada ação. Contudo, Giddens (2000) diferencia com cautela o processo de racionalização da ação e a motivação da ação, pois a motivação da ação enseja em si, muitas vezes, motivos não aparentes para o próprio agente da ação.

Assim, o termo motivação se torna processual, de modo que o agente busca em sua vida cotidiana, de acordo com o contexto em que está inserido e sua própria personalidade, uma "segurança ontológica", expressada em uma "autonomia do controle corporal" no ámbito de "rotinas previsíveis" (GIDDENS, 2009, p. 58). Assim, as motivações humanas estariam intimamente ligadas a processos de rotinização, sustentadas por "dispositivos protetores" que auxiliam o individuo em suas relações de confiança com outros, tais como familiares, amigos etc.

Lilleker e Koc-Michalska (2016), estudando os motivadores que dirigem a participação em meio digital no Reino Unido pré-eleitoral confirmaram a vinculação de motivações de cunho prosocial, tornando a participação um processo de self-presentation, onde o indivíduo não somente se apresenta nas interações em grupo nas mídias sociais, mas também precisa apresentar ideias que sejam apoiadas pelo grupo em que ele está inserido. Sentimentos de eficácia pessoal foram menos significativos do que aqueles incentivos de se sentir pertencente a um grupo.

Os pesquisadores não conseguem convergir sobre as motivações intrínsecas que estariam no cerne da questão de pertencimento a um grupo como motivador para participação política. Entretanto, se fizermos a ligação correta entre os pressupostos da agência apresentadas acima na teoria da estruturação e tais resultados empíricos, pode-se indicar que poderá haver motivações de busca contínua de segurança identitária, como também ontológica nas motivações para participação, especialmente em meio eletrônico.

\section{CONCLUSÃO}

Este ensaio teórico apresenta a problemática atual da participação eletrônica, a partir de um cenário de profundas mudanças tecnológicas que se alicerçam sobre o cotidiano de milhões de cidadãos no mundo inteiro. A partir de uma revisão da literatura da área de participação eletrônica, percebe-se que esse ambiente mutante, em que estamos inseridos nas primeiras décadas do século XXI, caracteriza-se por uma dificuldade de organização epistemológica dos saberes sobre o tema, em que não se sabe ainda o que rege e influência decisivamente a agenda dos participantes digitais (PINHO, 2011), nem tampouco seu comportamento e atitude em meio virtual (VICENTE; NOVO, 2014). Percebe-se também que ainda permanecem os grandes influenciadores habituais dos meios de comunicação de massa (SUSHA; GRONLUND, 2012) ao passo que perfis automatizados também conseguem influenciar a esfera pública (RUEDIGER, 2017).

Contudo, será o governo ainda o grande agente da questão, proporcionando oportunidades de participação (GARCIA, 2014; LIDÉN, 2016; BRAGA; GOMES, 2016) que se engendram na teia de agências que influenciam a agência do cidadão em participar. Porém, o dinamismo de regras do 
meio digital converge para uma progressiva ampliação das estruturas apresentadas pela tecnologiaem-prática dos cidadãos e empresas, o que influencia o modo como esse cidadão enxerga sua relação mediada com o governo.

A questão colocada da dimensão em que o campo de estudos em participação eletrônica se beneficia das ideias da Teoria da Estruturação é respondida parcialmente por este trabalho, tendo em vista que haveria a necessidade de um aprofundamento da questão da tecnologia-em-prática, uma vez que nos processos de participação eletrônica a borda de limite da organização se extende, ampliando a dificuldade de operacionalização do estudo, a partir de pelo menos três diferentes sistemas: o sistema tecnológico (intelecto artificial), o sistema cultural (intelecto coletivo) e o sistema psíquico (intelecto individual).

Este último, apresentou-se como especialmente importante neste ensaio teórico, através da aplicação do modelo de estratificação do self do agente, ideia que muitas vezes foi colocada de escanteio pela maioria dos teóricos que acompanharam o movimento da teoria da estruturação, mas que pode nutrir o questionamento de um dos grandes gaps de pesquisa da atualidade na área de participação eletrônica: quais são os fatores que influenciam o cidadão a participar eletronicamente. Neste ínterim, a monitoração reflexiva da ação se coligaria com as possibilidades levantadas na teoria de tecnologia-como-prática, em que os hábitos de uso de tecnologia adquiridos pelos cidadãos moldariam a forma como eles fazem participação em meio eletrônico.

Não esgotando o assunto em si, o trabalho começa a iluminar os anseios teóricos referentes à motivação para participação com fins cívicos, em que os cidadãos, restritos muitas vezes a um millieau que auxilia a configurar sua existência e realidade, tendem a buscar uma certa segurança ontológica em sua participação eletrônica, de modo a assegurar que a sua realidade de aceitação junto a seu grupo social não irá se modificar, facilitando a manutenção das condições que governam a continuidade de estruturas já dadas e portanto, da reprodução dos sistemas sociais como eles são.

Ousando refletir um passo mais à frente, a participação eletrônica por exemplo em mídias sociais, tem sido apresentada como aquela imbuída de menor impacto em sua autoeficácia, surge assim a hipótese final deste trabalho, de que as recompensas relacionadas a melhoria do bem-estar social produzido pela participação devem ser significativamente maiores do que o risco produzido pela possibilidade de conflito com os seus e perda do espaço de aceitação do grupo e consequente perda da segurança ontológica.

Assim, o cidadão em relação direta com as agências do governo e as estruturas sociais dos sistemas tecnológico e cultural, apenas consegue a possibilidade de rebelar-se destas estruturas, quando recebe apoio em suas motivações intrínsecas, especialmente quando seu self aparenta estar em um entorno caótico e inseguro. De outro modo, o cidadão tende a negociar suas ações no mundo, a partir de um cenário de apoio dos pares (sensação de pertencimento) e conhecimento das regras e recursos concernentes aos sistemas cultural e tecnológico (no caso da participação eletrônica, inclusão digital). Mas a racionalização da possibilidade de incerteza sobre sua segurança identitária também o move a se organizar, de modo a encontrar pares que o acolham em suas ideias e aparentem dispor das mesmas motivações que ele.

Em suma, os indivíduos estão em contínua busca por segurança identitária e ontológica e neste ínterim aceitam as regras do mundo virtual em busca da sensação de pertencimento e confiança 
no mundo que o cerca, principalmente quando a sensação de incerteza os acomete. Rebelar-se só é uma opção em conjunto, pois em nível individual a sensação de medo e desprotegimento é maior e mais amedrontadora. Ainda que cada um esteja fisicamente em sua casa, acessando e se comunicando individualmente, é provável que os significados compartilhados individualmente, insiram-se em agendas coletivas, assinaladas e negociadas no mundo virtual.

\section{REFERÊNCIAS}

ANDUIZA, E.; GALLEGO, A.; CANTIJOCH, M. Online political participation in Spain: The impact of traditional and Internet resources. Journal of Information Technology and Politics, v. 7, p. 356-368, 2010. Disponível em: <https://www.tandfonline.com/doi/ abs/10.1080/19331681003791891> Acesso em: 10 de set. de 2018.

BARLEY, S. R. Technology as an occasion for structuring: Evidence from observations of ct scanners and the social order of radiology departments. Administrative Science Quarterly, v.31, n.1, p.78-108, 1986.

BEST, S. J.; KRUEGER, B.S. Analyzing the representativeness of Internet political participation. Political Behavior, v. 27, p. 183-216, 2005. Disponível em: <https://www.jstor.org/ stable/4500191?seq=1\#page_scan_tab_contents> Acesso em: 10 de set. de 2018.

BRAGA, L. V.; GOMES, R. C. Participação eletrônica e suas relações com governo eletrônico, efetividade governamental e accountability. Organizações \& Sociedade, v. 23, n. 78, p. 487-506, 2016. Disponível em: <http://www.scielo.br/scielo.php?pid=S198492302016000300487\&script=sci_abstract\&tlng=pt> Acesso em: 10 de set. de 2018.

BRESSER-PEREIRA, L. C. A reforma do estado dos anos 90: lógica e mecanismos de controle. Lua Nova [online], n.45, p. 49-95, 1998. Disponível em: http://dx.doi.org/10.1590/S010264451998000300004. Acesso em: 27 de jun. de 2019.

BRESSER-PEREIRA, L. C. Da administração pública burocrática à gerencial. Revista do Serviço Público, ano 47, v. 120, n.1, p. 07-40, 1996. Disponível em: http://repositorio.enap.gov.br/ handle/1/1734. Acesso em: 27 de jun. de 2019.

BRIGHT, J.; MARGETTS, H. Big Data and Public Policy: Can It Succeed Where E-Participation Has Failed? Policy and Internet, v. 8, n. 3, p. 218-224, 2016. Disponível em: <https:// onlinelibrary.wiley.com/doi/full/10.1002/poi3.130> Acesso em: 10 de set. de 2018.

BRYANT, C. G. The uses of Giddens' structuration theory. Reihe Soziologie, v. 37, 1999.

Disponível em: http://nbn-resolving.de/urn:nbn:de:0168-ssoar-221872. Acesso em: 27 de jun. 2019.

COMITÊ GESTOR DA INTERNET NO BRASIL (CGI). Pesquisa sobre o uso das tecnologias de informação e comunicação no setor público brasileiro: TIC governo eletrônico 2015. São Paulo: Comitê Gestor da Internet no Brasil, 2016. 
CUNHA, M.A.; COELHO, T.; PRZEYBILOVICZ, E. Get into the club: positioning a developing country in the international e-gov research. EJISDC, n. 79, v. 4, p. 1-21, 2017. Disponível em: <https://onlinelibrary.wiley.com/doi/abs/10.1002/j.1681-4835.2017.tb00580.x> Acesso em: 10 de set. de 2018.

DAGNINO, E. 'We All Have Rights, But... Contesting Concepts of Citizenship in Brazil', In: N. Kabeer (ed.), Inclusive Citizenship: Meanings and Expressions, London: Zed Books, 2005.

DUNLEAVY, P. New Public Management Is Dead-Long Live Digital-Era Governance. Journal of Public Administration Research and Theory, v. 16, n. 3, p. 467-494, 2006. Disponível em: <https://academic.oup.com/jpart/article/16/3/467/934257> Acesso em: 10 de set. de 2018.

FOUCAULT, M. Governmentality. In: The Foucault effect: studies in governmentality. BURCHELL, G.; GORDON, C.; MILLER, P. (editores). Chicago: The University of Chicago Press, 1991.

GARCÍA, J. G. Gobierno Abierto: transparencia, participación y colaboración en las Administraciones Públicas. Revista Innovar. Colombia, v. 24, n. 54, 2014. Disponível em: <https:// revistas.unal.edu.co/index.php/innovar/article/view/46441> Acesso em: 10 de set. de 2018.

GIDDENS, A. A constituição da sociedade. 3.ed. São Paulo: Editora WMF Martins Fontes, 2009. GIDDENS, A. Central problems in social theory. Berkeley: University of California Press, 1979.

GIDDENS, A. Dualidade da Estrutura: Agência e Estrutura. Oeiras: Celta Editora, 2000.

IPEA. Relatório sobre participação social na Administração Pública Federal: Desafios e perspectivas para a criação de uma política nacional de participação [Documento Online] Disponível em: <www.dialogossetoriais.org> Acesso em: 29 ago. 2017.

KAGARISE, W.; ZAVATTARO, S. M. Social Media: How One City Opens the Evidence Black Box. Public Administration Review, v. 77, n. 4, p. 486-488, 2017. Disponível em: <https:// onlinelibrary-wiley.ez75.periodicos.capes.gov.br/doi/full/10.1111/puar.12696> Acesso em: 10 de set. de 2018.

KAVANAUGH, A.; TEDESCO, J.; MADONDO, K. Social Media vs. Traditional Internet Use for Community Involvement: Toward Broadening Participation. In: TAMBOURIS, E.; MACINTOSH, A.; BANNISTER, F. Anais 6th International Conference on Electronic Participation (ePart), Lecture Notes in Computer Science, p.1-12, Dublin, Sep. 2014. Disponível em: <10.1007/978-3662-44914-1 1>Acesso em: 29 ago. 2017.

KRUEGER, B. S. Assessing the potential of Internet political participation in the United States: A resource approach. American Politics Research, v. 30, n. 5, p. 476-498, 2002.Disponível em: <https://doi-org.ez75.periodicos.capes.gov.br/10.1177/1532673X02030005002> Acesso em: 10 de set. de 2018 . 
LEONARDI, P. M. Theoretical foundations for the study of sociomateriality. Information and Organization. [S.1.], v. 23, n. 2 p. 59-76, 2013. Disponível em: <https://doi.org/10.1016/j. infoandorg.2013.02.002> Acesso em: 10 de set. de 2018.

LIDÉN, G. Inequality in Local Digital Politics: How Different Preconditions for Citizen Engagement Can Be Explained. Policy and Internet, v. 8, n. 3, p. 270-291, 2016. Disponível em: <https://doi-org.ez75.periodicos.capes.gov.br/10.1002/poi3.122> Acesso em: 10 de set. de 2018.

LILLEKER, D.; KOC-MICHALSKA, K. Whats drive political participation? Motivations and mobilization in a digital age. Political Communication, v. 34, n. 1, p. 21-43, 2017. Disponível em: $<10.1080 / 10584609.2016 .1225235>$ Acesso em: 10 de set. de 2018.

MACINTOSH, A. Characterizing E-Participation in Policy-Making.PROCEEDINGS OF THE 37TH HAWAII INTERNATIONAL CONFERENCE ON SYSTEM SCIENCES2004 (HICSS-37). Anais...Island of Hawaii (Big Island): Computer Society Press, 2004. Disponível em: <doi. ieecomputersociety.org/10.1109/HICSS.2004.1265300> Acesso em: 10 de set. de 2018.

MERGEL, I. Building Holistic Evidence for Social Media Impact. Public Administration Review, v. 77, n. 4, p. 489-495, 2017.Disponível em: <https://doi-org.ez75.periodicos.capes.gov.br/10.1111/ puar.12780> Acesso em: 10 de set. de 2018.

\section{ORGANIZAÇÃO DAS NAÇÕES UNIDAS (ONU). United Nations E-Government Survey}

2016: E-Government in Support of Sustainable Development. ONU: New York, 2016. Disponível em: < https://publicadministration.un.org/egovkb> Acesso em: 13 de mar. de 2017.

ORLIKOWSKI, W. The duality of technology: rethinking the concept of technology in organizations. Organization Science, v. 3, n. 3, 1992. Disponível em:<https://doi.org/10.1287/ orsc.3.3.398>Acesso em: 10 de set. de 2018 .

ORLIKOWSKI, W. The sociomateriality of organisational life: considering technology in management research. Cambridge Journal of Economics. v. 34, p. 125-141, 2010. Disponível em:<10.1093/cje/bep058> Acesso em: 10 de set. de 2018.

ORLIKOWSKI, W. Using technology and constituting structures: A practice lens for studying technology in organizations. Organization Science, n. 11, v. 4, p. 404-428, 2000.Disponível em:<https://doi.org/10.1287/orsc.11.4.404.14600>Acesso em: 10 de set. de 2018.

OSBORNE, S. P. The new public governance? Public Management Review, v. 8, n. 3, p. 377-387, 2006.Disponível em:<https://doi.org/10.1080/14719030600853022> Acesso em: 10 de set. de 2018.

PAULA, A.; KEINERT, T. Inovações institucionais participativas : uma abordagem exploratória da produção brasileira em Administração Pública na RAP e no EnAPG ( 1990-2014 ). Cad. EBAPE. BR, v. 14, n. 5, p. 744-758, 2016.Disponível em:<http://www.scielo.br/pdf/cebape/v14n3/16793951-cebape-14-03-00744.pdf>Acesso em: 10 de set. de 2018. 
PHANG, C. W.; KANKANHALLI, A. A research framework for citizen participation via eConsultation. In: PROCEEDINGS OF THE ELEVENTH AMERICAS CONFERENCE ON INFORMATION SYSTEMS.Omaha, NE, USA.Proceedings of the AMCIS. Paper 145, 2005. Disponívelem:<https://pdfs.semanticscholar.org/28cd/3e0c2f0a61b6862aab323af48422873d73b8. pdf>Acesso em: 10 de set. de 2018.

PIÑEDO-NEBOT, C. P. Posibilidades y condicionamientos de los presupuestos participativos Posibilidades. Temas para el debate, n. 113, p. 1-6, 2004.Disponível em: <https://dialnet.unirioja. es/servlet/articulo?codigo=416896> Acesso em: 10 de set. de 2018.

PINHO, J. A. Sociedade da Informação, Capitalismo e Sociedade Civil: Reflexões sobre Política, Internet e Democracia na Sociedade Brasileira. RAE, São Paulo, 51, 1: 98-106, 2011. Disponível em: http://www.scielo.br/scielo.php?script=sci_arttext\&pid=S0034-75902011000100009. Acesso em: 27 de jun. 2019.

POLAT, R. K. The Internet and political participation - Exploring the explanatory links.

European Journal of Communication, v. 20, n. 4, p. 435-459, 2005.Disponível em:<https://doiorg.ez75.periodicos.capes.gov.br/10.1177/0267323105058251>Acesso em: 10 de set. de 2018.

POOLE, M; DESANCTIS, G. Understanding the use of group decision support systems: The theory of adaptive structuration. In: FULK, J.; STEINFIELD, C., eds., Organizations and communication technology. Newbury Park: Sage, 1990.

RICART, R. M.; UBALDI, B. Como planejar governos digitais que apoiem o crescimento inclusivo e sustentável, na América Latina e Caribe. In: BARBOSA, Alexandre F. (Coord.) Pesquisa sobre o uso das tecnologias de informação e comunicação no setor público brasileiro: TIC governo eletrônico 2015. São Paulo: Comitê Gestor da Internet no Brasil, 2016.

RUEDIGER, M.A. Robôs, redes sociais e política no Brasil [recurso eletrônico]: estudo sobre interferências ilegítimas no debate público na web, riscos à democracia e processo eleitoral 2018. Rio de Janeiro: FGV, DAPP, 2017.

SABIONI, M. et al. Contextos (in)adequados para o engajamento cidadão no controle social. Revista de Administração Pública, v. 50, n. 3, p. 477-500, 2016.Disponível em: <10.1590/0034-7612153518>Acesso em: 10 de set. de 2018.

SÆBØ, Ø.; ROSE, J.; SKIFTENES FLAK, L. The shape of eParticipation: Characterizing an emerging research area. Government Information Quarterly, v. 25, n. 3, p. 400-428, 2008. Disponível em: <http://dx.doi-org.ez75.periodicos.capes.gov.br/10.1016/j.giq.2007.04.007>Acesso em: 10 de set. de 2018.

SANFORD, C.; ROSE, J. Characterizing eParticipation. International Journal of Information Management, v. 27, n. 6, p. 406-421, 2007.Disponível em: <https://doi.org/10.1016/j. ijinfomgt.2007.08.002> Acesso em: 10 de set. de 2018. 
SCOTT, S. V; ORLIKOWSKI, W. J. Reconfiguring relations of accountability: Materialization of social media in the travel sector. Accounting, Organizations and Society, v. 44, n. 1, p. 26-40, 2012. Disponível em: <https://doi.org/10.1016/j.aos.2011.11.005>Acesso em: 10 de set. de 2018.

SEO, J.; HASAN, M. Where are e-government in South Asian Countries? A comparative approach. A Research Journal of South Asian Studies, v. 30, n. 2, p. 7-24, 2015. Disponível em: <https:// pdfs.semanticscholar.org/2e96/8173c2109cab46a2a5561fdd34b9369639ec.pdf>Acesso em: 10 de set. de 2018.

SHAO, P.; WANG, Y. How does social media change Chinese political culture? The formation of fragmentized public sphere. Telematics and Informatics, v. 34, p. 694-704, 2017. Disponível em: https://www.sciencedirect.com/science/article/abs/pii/S0736585316302878. Acesso em: 27 de jun. de 2019.

SUSHA, I.; GRÖNLUND, Å. EParticipation research: Systematizing the field. Government Information Quarterly, v. 29, n. 3, p. 373-382, 2012. Disponível em: <https://doi.org/10.1016/j. giq.2011.11.005>Acesso em: 10 de set. de 2018.

TUFEKCI, Z. Twitter and tear gas: the power and fragility of networked protest. Washington: Yale University Press, 2017.

VICENTE, M. R.; NOVO, A. An empirical analysis of e-participation. The role of social networks and e-government over citizens' online engagement. Government Information Quarterly, v. 31, n. 3, p. 379-387, 2014.Disponível em: <https://doi.org/10.1016/j.giq.2013.12.006> Acesso em: 10 de set. de 2018.

WILSON, W. The study of administration. Political Science Quarterly, v. 2, n.2, p. 197-222, 1887. 